\title{
Floating down the River: Vietnamese Community-led Social Innovation
}

\begin{tabular}{|r|l|}
\hline Journal: & Social Enterprise Journal \\
\hline Manuscript ID & SEJ-04-2020-0024.R2 \\
\hline Manuscript Type: & Research Paper \\
\hline Keywords: & $\begin{array}{l}\text { Embeddedness, Social Enterprise, Social Innovation, Networks, } \\
\text { Community Energy }\end{array}$ \\
\hline
\end{tabular}

\section{SCHOLARONE \\ Manuscripts}


Title

Floating down the River: Vietnamese Community-led Social Innovation

\begin{abstract}
Purpose: The paper explores the barriers facing social enterprise led community energy projects in Vietnam, to understand the barriers and enablers of social innovation in transitioning economies. In doing so the research seeks to identify whether the Vietnamese ecosystem is conducive to sustainable community energy projects and social innovation more broadly.
\end{abstract}

Design/Methodology/Approach: The research utilised a qualitative, case-study based methodology to explore institutional barriers to social innovation in the context of three community-led energy projects in Northern Vietnam. Interviews and focus groups were undertaken with 17 individual stakeholders within or engaged with the three case-studies. The qualitative data utilised was analysed utilising Constant Comparative Method, a method of analysis based in Grounded Theory that allows for iterative analysis of the data gathered.

Findings: Social enterprises and their beneficiaries are reliant on their ability to network, but with the Vietnamese government actively involved in the markets there are significant barriers standing in the way of these networking opportunities. Communities with little political capital are alienated from state institutions, whilst enterprises that offer alternative solutions to governmental priorities, are seen as competitors by political agents.

Originality/Value: Applying Granovetter's theory of 'embeddedness' and Herold et al. (2019) and Popov et al.'s (2016) theories on institutional centrality and power distribution, this paper seeks to add to our understanding on the impact large, hegemonic institutions can have on the networking ability of social enterprises and their beneficiaries.

\title{
Key Words
}

Embeddedness; Social Enterprise; Social Innovation; Networks; Community Energy.

\section{Introduction}

Electricity usage in Vietnam has grown rapidly in recent times, whereas in 1990 only $54 \%$ of the population had access to power, that figure now stands at $98 \%$ with the country becoming a net importer to meet demand (Urban, 2018). The increase in energy consumption has primarily been driven by the states adoption of the 1986 Doi Moi economic reforms, which saw the planned economy transition toward liberalisation (Hansen, 2017). In order to control the outcomes of liberalisation, the state has primarily aimed investment into cities, with urban areas benefiting from being close to both economic and political centres of power (Thayer, 2009). The state has, however, also made great efforts in rural electrification, with $95 \%$ of rural households having access to electricity by 2008 (Nguyen et al, 2019). Despite these achievements, energy poverty is still a reality for communities either disenfranchised by the state, or living in areas where it is unable to build a suitable energy infrastructure, for example, in mountainous regions.

Social enterprises have sought to resolve this problem through the process of social innovation, in particular the implementation of small scale community-funded renewable energy projects. The literature on the implementation of such projects has expanded greatly, with particular focus on the relationship between the technology, local community and wider society (Wirth, 2013; Maruyama, 
2007; May and Diesendorf, 2018; Kooji et al., 2018). A regular issue raised in the literature is the barriers to success when trying to community energy projects in areas where there are vested interests (Kooij et al., 2018). In the case of Vietnam, the dual approach of market liberalisation combined with one-party political control has created an ecosystem whereby personal and business networks have become key to success, granting as they do patronage and access to resources (fiscal and otherwise). In doing so, the paper seeks to present a picture of how community-led renewable energy projects can emerge and succeed in transitional economies, despite 'embedded' structures of inequality and vested interests being present.

This paper adopts a theoretical framework centred on Granovetter's work on embeddedness (1985) and social structures (2005), and how these shape economic outcomes. Further, the paper aligns this with Weber's (1978) work on power, and how access to resources shapes individuals' (and hence a community's) ability to engage in social action. These dual theoretical approaches are embedded within a wider discussion of institutional factors with regards to institution centrality and stakeholder salience (Herold et al., 2019), as well as offering a critique of institutional models that suggest asymmetrical distributions of power are 'accidental' (Popov et al., 2016). Instead, this paper argues that such power imbalances are purposely built into socioeconomic systems, as a means to control resource flow. The paper therefore makes a significant and original contribution to knowledge in the areas of community-funded renewable energy and social enterprise ecosystem development, by demonstrating how institutional barriers and embeddedness within social networks, shape the forms of social innovation that emerge.

\section{Social Innovation and Social Entrepreneurship Globally}

Heiskala (2007:519) defined social innovation as "changes in the cultural, normative or regulative structures [or classes] of the society which enhance its collective power resources and improve its economic and social performance". The role of social innovation can therefore be seen as one of empowerment, with a specific focus on those individuals/communities that are socially disadvantaged. Social innovation can emerge as products/services, marketplaces and/or processes (Nicholls and Ziegler, 2014) and varies across different regional and national contexts (Bacq and Janssen, 2011; Mulgan, 2006). In Asia generally the most prominent emergent form of social innovations are social enterprises (Sengupta and Sahay, 2017), defined as self-sustainable marketbased organisations that seek to reduce social inequality (Dart, Clow and Armstrong, 2010; Nicholls, 2007). However, when defining social innovation, it is important to recognise that social enterprise constitutes only one type of innovation, and that others exist. Indeed, social innovations can emerge from civil society, Non-Governmental Organisations, higher education, government and private sector stakeholders (Murray, Caulier-Grice and Mulgan, 2010).

For the purposes of this paper, it is important to better understand how the emergence of social innovations (and specifically community-led social enterprises) are constrained by wider ecosystem factors, specifically in relation to institutional constraints. Whilst prior research has demonstrated the high levels of impact delivered by bottom-up social innovations globally (Kruse et al., 2014), the reality in different regions is that social innovation as an ecosystem can be often overly driven (and constrained) by top-down factors. Given that the role of social innovations are to change cultural, normative and regulative structures in society (Heiskala, 2007), there is therefore a potential systemic bias within countries or ecosystems to inhibit the emergence of said innovations. Such bias can translate into a lack of legitimacy (Suchman, 1995) for social innovators within systems that are unfavourable to social innovation. Certainly, from a Weberian perspective, dominant stakeholders can use institutional mechanisms to limit the social action of others, in order to prevent systemic change from occurring (Weber, 1978). Furthermore, the work of Popov et al. (2016) has demonstrated that 'accidental' factors can also institutionally constrain social innovators, through institutional 
dysfunctions inherent to the country in question. Therefore, from an institutional perspective, institutional barriers within the ecosystem could exist both by deliberate design and due to inefficiencies. Nevertheless, it must be noted that institutions are not islands within society, but rather are actively shaped by the stakeholders that engage with them (Herold et al., 2019); the institutional logics that can constrain social innovation are themselves the result of stakeholder actions. This means that social innovation is shaped in a continuous cycle of institutional and stakeholder interaction.

Globally, social innovations and social enterprise have emerged as potential solutions to societal problems, driven by an increased focus on how to alleviate the social problems that have arisen and appear to be unsolvable using traditional market and public sector models. Whilst it is important not to underplay the localised and culturally relativistic nature of many social innovations, it is also critical to recognise that its emergence is based within the emergence of supra-national social norms (Do and Fernandes, 2020). Indeed, models of social innovation such as social enterprise can be argued to be both the result of globalisation and the spread of ideas, as well as localised resistance to the disempowerment felt by many communities due to globalisation (Author's Own). The emergence of the United Nations Sustainable Development Goals (SDG) from which SDG7 (Affordable and Clean Energy) is most pertinent to this study, has helped to solidify this growth. Prior research (Eichler and Schwarz, 2019) has also identified the relativistic nature of social innovations globally through the SDG framework, with the focus of social innovations in developing countries generally being tied to SDG1: No Poverty, SDG3: Good Health and Wellbeing, and SDG4: Quality Education, and SDG8: Decent Work and Economic Growth; whilst in developed countries the focus has been centred on SDG11: Sustainable Cities and Communities, SDG3: Good Health and Well-Being and SDG10: Reduced Inequalities ${ }^{1}$.

The development of supportive ecosystems for social innovation has been typified as being centred on strong stakeholder networks (Horgan and Dimitrijević, 2018), with low-power distance and pluralistic flows of resources (Author's Own). Further, the distribution of power within these networks and the way that this shapes resource flow is directly related to the strength of the ecosystem (Author's Own). Supportive ecosystems are also critical in delivering social innovations centred on energy justice (Hiteva and Sovacool, 2017), as the empowerment of communities through bottom-up social innovation is vital to the emergence and growth of community energy systems (Koirala et al., 2018). This refers to what Mulgan (2019:64) identified as the 'power test', whereby social innovation empowers people and they feel this empowerment. This type of bottom-up social innovation in the development of community energy projects is important precisely because it empowers communities to move from being passive consumers to active stakeholders (ibid), allowing socially disadvantaged individuals to engage in social action to direct social change. In addition, the role of ecosystem conditions could be posited to be very influential in this area, given that the SI Drive 'Atlas of Social Innovation' identifies only 44 social innovation projects worldwide focused on 'Energy Collectives' and 'Energy Services', with 41 of these being based in Europe (SI Drive, 2020)2. Within the Vietnamese context, the 'imap' of social innovation created by National Economics University in Hanoi, identifies only 32 energy and clean technology social innovations in Vietnam, all of which are based in the major urban conurbations of Hanoi ( $N=24)$, Ho Chi Minh City $(N=5)$ and Danang $(N=3)$ (NEU, 2020). However, given the aforementioned importance of stakeholder networks and institutional logics in the development of social innovation, how can the very communities that do not have access to said networks/institutions be empowered to solve their own energy needs?

\footnotetext{
${ }^{1}$ Globally it is highly probably that we will see a larger focus on SDG3 Good Health and Wellbeing in both developed and developing countries moving forwards with the Covid-19 outbreak still ongoing at the time of writing.

${ }^{2}$ Whilst we would not argue that SI Drive provides a comprehensive overview of global social innovations, it is interesting that their mapping has not identified any such projects in Asia and more specifically Vietnam (the three non-European social innovation projects were in Africa $(\mathrm{N}=2)$ and South America $(\mathrm{N}=1)$.
} 


\section{Economic Embeddedness and Institutional Theory}

Originally writing in 1973, Granovetter proposed two forms of the socio-economic network, strong and weak. The strong-network is made up of our strong, interpersonal relationships, which play a significant role in the creation of economic structures. The role of the strong-network occurs because the trust that comes with familiarity, offsets the risk of attracting 'free-riders' in groups, or individuals trying to benefit from a project without contributing (Granovetter, 2005). Building on this, Marsden and Campbell (1984) studied what the best indicator of a strong tie was, with 'emotional closeness' considered to be the most important factor in the development of the strong-network, over and above the amount of time of connected, intimacy (mutual confiding) and reciprocal services (Marsden and Campbell, 1984). We can see this manifest in the creation of group identities that community groups adopt when organising themselves to combat local energy issues. The denser the strong-network, the more protected it becomes from subversive messages, as nodes within the network repeatedly assert shared ideas and norms, reaffirming the proper way to behave within the community. This closeness allows the networked nodes to identify repeated problems that the community suffers from and work together in an attempt to develop the tools to fix them (Yalcin-Riollett et al., 2014). However, as the strong-network is built on shared social situations, the information from where solutions can be derived is limited due to the similarity of experiences. This can act to constrain social innovation and consequently the emergence of new solutions to problems (i.e. social enterprise), as the group becomes closed off to alternative influences. Therefore, if the strong-network is unable to use its own tools to solve a problem (and recognises this), it will look outwards towards its weak-network for inspiration (Granovetter, 2005).

This research develops Granovetter's embeddedness in line with the institutional theory hypothesised by Herold et al. (2019) whom combined institutional/stakeholder theory when investigating carbon disclosure strategies (Herold et al., 2019). Herold's work indicated that although stakeholders and companies are treated separately within different theoretical frames, the former have the ability to enforce their will on the latter if controlling material or financial resources. This is particularly salient within the Vietnamese social innovation climate, as external societal stakeholders are able to control market outcomes due to their much stronger influence on the state's economic and political networks then would be expected elsewhere. However, the current research suggests that as opposed to the monopolisation of power being incidental due to bad system design, as suggested in the work of Popov et al. (2016), the asymmetrical distribution of power is purposively built into Vietnamese networks (Popov et al., 2016). This relates to prior research around social innovation in general, which identifies barriers to resources (financial, political, intellectual, legal and human) as critical in enabling or stifling the emergence of innovations (Oeij et al., 2019).

Vietnam therefore offers a unique example of Granovetter's theory of embeddedness, as the influence of the Vietnamese Communist Party in the country's networks and the development of a state-centric economy (albeit built on market-liberalisation) has impacted upon what information gets shared, and who has the right to access it. The country also demonstrates how social networks in transitional economies can embed power disparities and further exclude already socially disadvantaged societies, if pluralising economic forces are not allowed to develop. Indeed, from a Weberian perspective (1978) this social embeddedness within the economy allows dominant actors to shape social action towards their own ends, and to prevent others from improving their own economic positions. However, to develop an embedded understanding of the community-led renewable energy market in Vietnam, it is first important to understand the Vietnamese economic context itself.

\section{The Vietnamese Context}


In 1986, Vietnam adopted the Doi Moi policies of economic reform as the state attempted to avert growing hardship by moving away from a centrally managed system into one driven by the markets. In order to protect its citizens from the risks of structural adjustment, therefore preserving its legitimacy as the protector of the people, the Vietnamese state built its new economic model on the foundations of its traditional political network, trusting governmental actors and political allies to put policy before growth (Thayer, 2009; Gamble, 2011). This patronage based system pulled much of the newly opened markets into the state's 'strong-network', with key actors ensuring that although the network would be dense, there would remain a top-down approach to power, with participants repeatedly seeing requests for preferred behaviours from a government willing to prosecute those who they considered to have mismanaged a state asset or chosen profit over the delivery of government policy (Nguyen, 2017). This controlled development of market liberalisation in Vietnam has caused the evolution of capitalism to be uneven, with researchers identifying three different economic systems operating across the country, namely: state capitalism; crony capitalism; and socialism. This has made it difficult for investors and enterprises to navigate properly, or partner with enterprises in other geographic areas who have different market experiences (Ngo and Tarko, 2017).

This development of the Vietnamese markets has largely influenced the behaviours of foreign investors, who traditionally offer a substantial source of funding for both social enterprises and other third sector/Non-Governmental Organisations (Dupuy et al., 2016). Investment freedom in Vietnam is poor, far below the world average in the 2019 Economic Freedom of the World Index (Vietnam is ranked $128^{\text {th }}$ of 180), with the state restricting various sectors of the economy (Index of Economic Freedom, 2019; Gamble, 2011). The difficulties in investing in the Vietnamese market have been partially offset by the creation of enterprise incubators that allow investors access to the countries small and medium businesses, including social enterprises. However, as these incubators are driven by societal stakeholders who are able to influence investor strategy, groups pursuing innovations that fall outside government policy, experience difficulty in gaining financial or business support. This creates an environment for social innovations that is sub-optimal and communities (and the social enterprises seeking to support them) from gaining institutional support and access to key stakeholder networks. This means that those with power can distort narratives to fit their own agendas, and that those without access to networks and resources (i.e. the socially disadvantaged) have their ability to engage in community-led renewable energy projects (social action) limited (Granovetter, 1985, 2005; Weber, 1978). This monopoly of power through social networks (both weak and strong) creates isomorphic tendencies within the ecosystem, as stakeholders are forced to conform or disappear.

This review has shown how the economic structure of the state can limit innovation when pluralisation is not pursued, with tensions created through the juxtaposition of state political control and increasing economic liberalism. This paper seeks to argue that whereas social enterprises have traditionally offered a means to overcome this inequality, the setup of the Vietnamese economy has raised barriers, significantly impacting their work. This is an important facet to understand, as the hybrid nature of social enterprises with their duality of social and economic missions, alongside their desire to empower the disadvantaged (Doherty, Haugh and Lyon, 2014; Douglas, 2015), makes their work crucial in the betterment of the lives of communities with little social, cultural or economic capital. The ability to connect the political, social, and economic spheres of the ecosystem enables social enterprises to reduce power-distance ${ }^{3}$ between communities and the state; whilst developing an understanding of how hegemonic institutions can affect the ability of social enterprises to empower communities, increases our knowledge of how power relations shape ecosystem development beyond the borders of Vietnam.

\footnotetext{
${ }^{3}$ Puumalainen et al. (2015) characterise high power-distance as a system in which large amounts of power are concentrated in the hands of a few actors.
} 


\section{Methodology}

The research sought to ascertain the perspectives of stakeholders involved within three case-studies on the issues and barriers that they faced in developing community-led solutions. Specifically, the research sought to answer the following two research questions:

RQ1: How can the economic and political ecosystem of Vietnam complement the development of sustainable community energy focused social enterprises?

RQ2: What are social or environmental factors that need to be addressed to allow for the successful implementation of social innovation within Vietnam?

The research adopted a qualitative methodological approach within a case-study paradigm, in which three purposefully selected case-studies were identified and selected for the research: one case-study was based in Hanoi; whilst the other two were based on Cat Ba Island, the largest island in the Cat Ba Archipelago (UNESCO, 2019). Yin (2014) identifies case-study research as providing a research approach whereby in-depth exploration of rich data can provide new theoretical insights that can be used to generalise in relation to specific phenomenon. Given that our access to potential case-study sites was limited, coupled with the nascent state of the community-led renewable energy sector in Vietnam, the opportunity to explore a small number of projects in-depth to generate new theoretical insights, provided a robust alignment with our research aims. Further, Yin (1994) also argues that casestudy research is best preceded by an empirical and theoretical understanding of the field gained through a literature review, and aligned with an analytical framework. This aligns with the Straussian grounded theory approach adopted in this study, in which we sought to identify qualitative themes that were grounded in the experience of the participants (bottom-up), but in which our initial thinking was informed by the prior literature and academic theory (top-down) (Corbin and Strauss, 1990).

A purposeful sampling technique also allowed engagement with people deliberately based upon their perceived expertise, knowledge and experience in relation to the phenomenon being explored (Higginbottom, 1994). The case-studies were selected at the local, community level; that is, each casestudy represented a specific local community that experienced problems and for whom working with social enterprises or other partners had presented them with renewable solutions to their energy needs. Within the case-studies, relevant stakeholders were engaged through semi-structured interviews, including: community members (the beneficiaries); the social entrepreneur and the staff supporting them (social enterprise); and local government/management officials (where applicable). In addition, the perspectives of academic experts in relation to the barriers facing community-led renewable energy projects were sought through a focus group, and this data is used as a point of triangulation between the three case-studies, so as to better understand the wider energy sector context in Vietnam. Table 1 below details those individuals who participated. In total, 17 individuals participated across the interviews and focus groups, whilst observations of the projects were also undertaken, so as to inform the researchers' knowledge of the projects and their context.

\section{[Insert Table 1 here]}

Semi-structured interviews ${ }^{4}$ provide the research with a flexible tool, with which certain important themes identified through the literature review and the theoretical framework could be explored, but in which the participants were also free to explore issues of importance to them (Myers and Newman, 2007). This allowed the research to both examine top-down theoretically derived phenomenon (Yin, 1994), but also ensure that the bottom-up 'grounded' perceptions of participants were captured

\footnotetext{
${ }^{4}$ In some cases, recordings were not possible and instead extensive notes were taken. Quotes from these interviews may not be verbatim and where this is the case they will be accompanied with an asterisk.
} 
Case-study 1: This case-study represents a floating village in Hanoi, made up of residents originally barred from living in the city having relocated from remote northern areas in the early 1990s. Since relocating to the Red River, the community has been actively involved in the cities growing informal/casual economy and is one of the beneficiaries of a green-energy social enterprise (SE1) who have provided the village with renewable energy systems, the community being isolated from the national grid. SE1 provides this service across Vietnam and is funded by donors and through competition wins. They have worked with the university, but have been unable to find wider political support for their work.

Case-study 2: This case study represents a community of pig farmers located on Cat Ba Island, Vietnams largest island east of Hai Phong city (Vietnam's third largest city). The pig famers run small scale operations and sell their stock to slaughterhouses who provide meat to the hotels serving the islands growing tourist industry. They were the beneficiaries of a Biogas project rolled out by the local government through the farmer's union, a system which turns the pig waste into gas and water. Within the research further networking was found between a farmer and a hotel, who provided waste food for the pigs in order for them to be considered organic, raising the price he could ask from the slaughterhouses.

Case-study 3: A second community engaged on the island were the farmers on floating fisheries, a concept developed by the government. Located off the coast of Cat Ba Island in an archipelago they are unable to be connected to the national grid, but due to their economic power they have been able to provide themselves with renewable energy systems to power their farms. This is due to them being able to sell their stock for inflated prices to the island's hotels, though some have also developed floating hotels and tours for the islands visitors around the archipelago.

The interviews were analysed utilising Constant Comparative Method (Glaser and Strauss, 1967; Lincoln and Guba, 1985), an iterative approach based in grounded theory and utilised for the qualitative analysis of text (i.e. interview transcripts) (Glaser and Strauss, 1967). In CCM categories 'emerge' from the interview data via inductive reasoning, rather than coding to predetermined categories (Maykut and Morehouse, 1994). This allows the research to therefore seek bottom-up answers to complex questions 'grounded' in participants' experience, whilst also allowing for theoretical and empirical information to inform the research at the pre-data gathering stage through a Straussian approach to grounded theory (Corbin and Strauss, 1990). Throughout the research 27 units of analysis emerged, leading to eight categories and ultimately three themes. These themes

\footnotetext{
${ }^{5}$ The research team recognises the limitations of an approach whereby the beneficiaries were interviewed in the presence of a local government official. In order to gain access to the participants this was at points unavoidable, and acts as one of the significant limitations of the research. However, given the focus of this paper on the role of the government in shaping social innovation in Vietnam, it also offers an interesting insight into the ecosystem constraints that exist.
} 
were: 'The Funnelling of Investors', 'Monopolisation of Networking Opportunities', and 'Distance Between Social and Political Priorities' (see Figure 1).

\section{[Insert Figure 1 here]}

\section{The Funnelling of Investors}

The social enterprise incubators in Vietnam have been set up in order to aid international investors who are seeking to invest in the state, by offering support and guidance in the hard to predict marketplace. The incubator P01 is working with is backed by both the United Kingdom and Vietnamese governments, and works with consortiums in the United States and Europe.

"We worked with consortiums overseas [...] US, UK and some other countries......So we are funded by our two main donors, who are the UK government and Ho Chi Minh Government" (I01 - Investor).

These partnerships add legitimacy to an incubator operating in an economy where the internal stakeholders are unsure of the government's attitudes toward foreign investment and how well it is set-up to protect new enterprises.

"The government needs to change their mindset" (P02 - Incubator Member)

"Our country has no industrial property protections" (P01 - Social Enterprise).

These concerns, along with the work of Gamble (2011), Ngo and Tarko (2017) and Thayer (2009) indicate that the incubators, investors, and involved businesses understand that the Vietnamese economic environment is difficult to navigate. This has, however, led to an asymmetrical relationship in terms of what each party is trying to achieve. The incubators are seeking to improve the social impact of the enterprises they support, and although their international partnerships have allowed them to invite experts in to help create support and knowledge networks, their partners are driven by profit.

"They'd prefer to do other business to earn easy money" (P02 - Incubator Member)

"We give seed funding to a lot of enterprises. We set goals and if they meet them they can get further funding and we will take equity in the business"* (103 - Incubator Investor).

This means that social enterprise incubators are not a system open to all, with the potential profitability of an investment being the primary driving factor behind any funding, something often not achievable for community energy projects (albeit they are often sustainable).

For enterprises such as SE1, the financial targets of the incubator system are significant barriers due to their primacy of their social missions. In general terms, investors will seek to increase their returns on investments through price rises, cost-reduction or volume increases. The solar panels cost $\$ 170$ to the community and many are already involved in micro-financing in order to fund the purchase, making price increases impractical. The costs involved with the solar panels are set due to the technology involved, and the wind turbine system utilises refurbished pots and pans meaning both systems are already at their lowest cost-points. Finally, although SE1 is interested in increasing its outreach, the communities that the enterprise serve remain economically weak. SE1 feels that this is enough to turn both the incubators and their international investors away. For the enterprise, the majority of investment they have received has been through donors or competition wins, which are sporadic in nature, leaving its future perpetually insecure. However, SE1's reliance on the incubator 
Indeed, P01, a social enterprise, indicated that their own experiences with the incubator had led them and their colleagues to consider the commercialisation of their work. However, P01 wasn't actively involved in their enterprise's commercialisation, instead the incubator took responsibility for it.

"Not only protect them, but he may create for me, for example, a smaller SME or some small company to commercialise it" (P01 - Community Member).

The absorption of this responsibility suggests there is little up-skilling of the enterprise managers, who are instead reliant on the incubator to commercialise their products. This is important in the Vietnamese context as it has been noted in prior research that the country's social enterprises are deeply embedded within their own cultural contexts and struggle to work with international partners (Easter and Conway Dato-On, 2015). In order for this to change, it's important that social enterprises can share knowledge with one another on how to navigate international relationships. However, this information is embedded into the incubator network many organisations are alienated from. Although incubated enterprises are able to take advantage of the knowledge pool created by the incubators, they are unable to disseminate that information 'downstream'.

Seeking horizontal nodes in a weak-network (partners of equal social, political or economic standing) has been shown to benefit enterprises when seeking to compete with established or embedded powers (Kooij et al., 2018). This knowledge transfer is key in bridging the strategic gaps within Granovetter's weak-networks; however, with the incubators not up-skilling their beneficiaries, SE1 is unable to find the information needed to bridge their gap in creating a sustainable business. This limits P01's ability to share its learning with other social enterprises, creating a knowledge monopoly in the Vietnamese ecosystem.

\section{Distance Between Social and Political Priorities}

The previous two themes could suggest that the asymmetrical development of the incubator network and the alienation of social enterprises who demonstrate low profitability, is an accidental system 
design as suggested in the institutional theory of Popov et al (2016), with incubators and investor behaviour coerced by the wider Vietnamese environment (ibid). However, an exploration of how the incubator operates suggests asymmetrical distribution of resources is a deliberate design. P01's incubator is backed by the Ministry of Science and Technology, who's goal it is to combat climate change. Due to it prioritising this, the incubator applies a top-down approach when seeking out enterprise partners, ensuring that potential enterprises are politically suitable. To aid this, they call upon experts within their network and create panels to discuss the potential of the businesses, panels which exclude communities themselves:

"We invite five or six people, one in the technical, one in the business, one in the social, one in the banks, investor, something like. So they come along, they sit at one table and then we discuss together about the potential ideas, potential of the business" (I01 - Incubator)

This top-down approach and the alienation of the community from decision-making, is impactful on the enterprises that work with them and offer alternative solutions to social problems. In practice, we can see this impact on the work that SE1 does, along with its continued distance from local political actors, through its inability to gain support and funding from incubators despite delivering a sustainable model. The Vietnamese government has proactively worked toward green energies, and adopted policies to further that goal, namely 'The Green Growth Strategy' (2012), the 'Green Growth Action Plan' (2014), and the 'National Strategy on Climate Change' (2011). Despite this, SE1 has found itself unable to partner with political actors in its offering of alternative energy for small communities disconnected to the national grid. Markard (2011) suggests that the key cause may be that as established technologies and practices (such as the incubators) are highly entwined with political and institutional practices, social enterprises like SE1 could be seen as competitors not partners.

This is further embedded into the Vietnamese environment, as access to technologies is funnelled through the incubators. Companies or communities who require either technology or access to a service supported by the incubator will post their needs on the incubator's systems. The incubator will them match them with other partners they have worked with previously.

"They will post their needs or they post their technology on our system" (101 - Incubator)

"At the same time the local company posts their needs, sometimes they need to transfer technology or they need the service, something like that. So we are matching them together so we come from both sides" (I01 - Incubator)

The technologies and partners available through the incubator system have already been through the political processes that allow them to access the incubation system. It was also suggested that the incubator may be filling one of the government's own strategic gaps with the state's social unions (government supported mass organisations) not being effective in the markets the organisation is involved in.

"The unions, the social union is not great, not yet, and not really works well and develops in Vietnam. So that's why it's very difficult to ask them to be involved in some kind of doing business like us." (101 - Incubator)

This is further supported by government support innovation programmes in the North of the country. Energy based innovations have been successful rolled out by both the farmers union and the government-led outreach to pig farmers, and the other farmers have been able to access similar technologies offered by SE1 (who don't operate in the area) through their economic strength. 
"We visited the farmers and used leaflets to tell people about the projects" (G02- Government Official).

Such institutional processes also create uniform logics that increase isomorphism in the ecosystem, with emergent homogeneity across social innovations (Herold et al., 2019). They are therefore excluded from the very stakeholder networks that convey resources to the 'chosen', and become effectively disembedded from economic structures (Granovetter, 2005).

This demonstrates what can be viewed as the deliberate design of institutional systems to retain power within the hands of key stakeholders (namely investors, incubators/universities, and government), both creating institutional dysfunction (Popov et al., 2016) and increasing the powerdistance within the ecosystem (Puumalainen et al., 2015). However, contrary to Popov et al.'s (2016) arguments, such dysfunction is not accidental, but rather a deliberate stakeholder strategy (Herold et al., 2019), designed to limit the power of (and hence social action) of social innovators within the ecosystem. This actively constrains social innovation in Vietnam and limits the growth of social enterprises operating in this area.

\section{Discussion}

Through Granovetter's (2005) theoretical lens of "embeddedness", this paper has sought to explore whether Vietnam's economy is complementary to the development of successful and sustainable community energy social enterprises, and whether any social or environmental factors needed to be addressed. The research presented seeks to add to our understanding of the impact a large and politically powerful node, can have on the ability of groups to traverse their weak-network as potential partners and nodes react to accommodate its actions. In doing so, the research combines Granovetter's (ibid) work with institutional theory, in order to show the complex interplay that exists between institutions and stakeholders, with the most powerful stakeholders able to shape institutional logics and societal discourse (Herold et al., 2019). As with all institutional design, this leads to accidental dysfunction in the logics (Popov et al., 2016), but in the case of Vietnam also deliberate dysfunction designed to exclude the socially disadvantaged. Indeed, by limiting the legitimacy and social action (Suchman, 1995; Weber, 1978) of the villagers and farmers included in these casestudies, the Vietnamese government is able to retain control of the social innovation ecosystem (Gamble, 2011). The result is the constraint of bottom-up social innovation, and hence the reduction in impact from said innovations (Kruse et al., 2014).

The government-supported incubator systems studied are seemingly a necessary accommodation for investors looking for additional protection and support whilst navigating the new Vietnamese economy. However, whilst incubators have been able to build relationships with financially strong partners and create knowledge-sharing networks for the enterprises involved in the systems, it has had an impact on the country's wider social enterprise environment. The inability to prove that a financier will be able to get a strong return on any investment, excludes them from the incubator system and alienates them from any related networking opportunity. With the incubator taking responsibility for the 'business' side of the relationship they have with the involved enterprises, there is little up-skilling of the owners, meaning that the 'novel' information (how to build networks, navigate the markets, and commercialise an idea) is not available (Yalcin-Riollett et al., 2019; Kooij et al., 2018; Sovacool and Drupady, 2012; Leal, 2011). The up-skilling of less knowledgeable partners has been a priority within other countries where actors have sought to create self-sustaining projects. In Panama, the school-parent associations were utilised in order to better preserve the project and encourage participation, whilst the outreach of partners working with groups in France and Laos is based on knowledge-sharing rather than the absorption of responsibility (Madriz-Vargas et al., 2017; Yalcin-Riollet et al., 2014; Leal, 2018). This, it could be argued, is a result of the Vietnamese 
partnerships being built on a transactional basis with the incubators offering commercial support in exchange for technology suiting governmental priorities. This is the deliberately designed institutional dysfunction in action (Herold et al., 2019).

With the incubators being an extension of these governmental priorities, there is also evidence of a gap between social and political priorities, with the incubator not including the union in its discussions when seeking out new enterprises. Social enterprises often operate within this gap, as where community issues are not necessarily part of the government's priorities, they actively seek to resolve problems they have identified utilising the markets and other available tools (Leal, 2018; Yalcin-Riollett et al., 2014; Kooij et al. 2018; Madriz-Vargas et al., 2017). However, in the Vietnamese context, enterprises operating outside of the incubation system could be seen as competitors, rather than potential partners, placing further barriers toward them getting political support. This support is crucial for all levels of the social enterprise environment in Vietnam, with political capital being the key to accessing further support.

Figure 2 below illustrates a systemic exemplar of the data presented in this paper, by demonstrating how access to weak- and strong-network nodes for the socially disadvantaged can inhibit or enable their ability to access resources and support for social innovations. At the macro-level the dominant stakeholders within the Vietnamese ecosystem (notably the government and international investors) emerge from competing paradigmatic discourses (state versus market) that create hybrid tensions in the ecosystem. These tensions are driven by state policy and discourse, as well as investors logics centred on profit and scalability. These tensions feedback into the state sector through market pressures, and the market through the social innovation products and services that do emerge. Conversely and despite these tensions, both the state and investors create the same coercive isomorphic tendencies through the support offered (political and financial) to incubators/unions for renewable energy innovations. The result are dysfunctional institutions constraining social innovation (Herold et al., 2019), both through accidental (Popov et al., 2016) and deliberate design. The state seeks to deliberately design these dysfunctions as a means to control the development of market forces and the types of social innovation that emerge, whilst the finance provided by the market (and permitted by the state) creates accidental dysfunctions i.e. sustainable, but not highly profitable social innovations, are excluded.

At the micro-level socially disadvantaged communities develop social innovations, often with the support of social enterprises, as a form of bottom-up social innovation. Despite these bottom-up social innovations having the potential to be highly impactful (Kruse et al. 2014), the ultimate success of these innovation rests not on their efficacy, but instead on the strong and weak network nodes of the communities themselves. The weak and strong-network nodes required to gain access to institutional support (Granovetter, 1985; 2005) and the high power-distance (Puumalainen et al., 2015) that exists within the Vietnamese ecosystem, leads to the potential exclusion of disadvantaged communities. For those communities that do have strong network nodes, access to the incubators/unions is possible as they are trusted by political actors; but for those that do not have strong network nodes, they have to utilise their weak network nodes, which do not always lead to incubator/union access, and in some cases leads to innovation failure. Where innovation failure does occur ${ }^{6}$, the result is embedded disadvantage, as the communities see that they are excluded from sustainable community renewable energy platforms. This disempowerment reduces the likelihood of further bottom-up social innovations being developed, hence constraining community social action (Weber, 1978). Whilst the social enterprises discussed in this paper, and to a lesser degree the unions, can use their hybridity to overcome these tensions and isomorphic tendencies (Doherty, Haugh and Lyon, 2014; Douglas, 2015), the reality is that without access to weak and strong-network nodes within the state and market, such

\footnotetext{
${ }^{6}$ It should be noted that innovation failure can also occur due to the innovation being unviable (Popov et al., 2016). Failure cannot purely be attributed to social networks and institutional design.
} 
solutions are doomed to remain small-scale and limited in their sustainability, as the social entrepreneurs and communities are unable to reshape institutional logics and ecosystem conditions in their favour. Without social innovations that can empower people to drive their own change (and recognise their empowerment), either as social entrepreneurs or more broadly as social innovators, truly innovative bottom-up change cannot occur (Mulgan, 2019).

\section{[Insert Figure 2 here]}

\section{Conclusion}

In summary, this paper has sought to show how bottom-up social innovation is constrained within one-party state, transitioning economies through the deliberate creation of institutional environments by dominant stakeholders. The resultant institutional dysfunction excludes the socially disadvantaged from becoming social innovators and leaves them disempowered and disenfranchised. This paper makes an original contribution to knowledge by showing how social innovation, and specifically social enterprise, are constrained in transitioning economies, particularly those with high degrees of centralised political control. By placing this within a framework centred on institutional theory and stakeholder network theory, the paper also seeks to show how institutional logics and stakeholder networks shape and reshape each other in social innovation ecosystems. Whilst the research is focused on community energy innovation and takes place in only one country, we believe that the emergent themes have applications globally in understanding how to better shape bottomup led social innovation. Nevertheless, further research that could empirically test this theoretical approach across a number of transitioning economy ecosystems would further develop scholarly understanding in this area.

\section{References}

1. Alam, S. Hashim, N., Rashid, M., Omar, N. and Ismail, M. (2014), "Small-scale households' renewable energy usage intention: theoretical development and empirical settings", Renewable Energy, Vol. 68, pp. 225-263.

2. Bacq, S. \& Janssen, F. (2011), "The multiple faces of social entrepreneurship: A review of definitional issues based on geographical and thematic criteria", Entrepreneurship \& Regional Development, Vol. 23 No. 5-6, pp. 373-403.

3. Callon, M. (2007), Actor-Network Theory - The Market Test: Technoscience - The Politics of Interventions, Oslo Academic Press, Oslo.

4. Corbin, J. and Strauss, A. (2003), "Grounded Theory Research: Procedures, Canons, and Evaluative Criteria”, Qualitative Sociology, Vol. 13 No. 1, pp. 3-22.

5. Dart, R., Clow, E. \& Armstrong, A. (2010), "Meaningful difficulties in the mapping of social enterprises", Social Enterprise Journal, Vol. 6 No. 3, pp. 186-193.

6. Dhondt, S., Oeij, P. and Schroder, A. (2018), "Resources, constraints and capabilities", In: Howaldt, J. Kaletka, C., Schroder, A., Zirngiebl, M., eds, Atlas of social innovation - New practices for a better future. Dortmund, Germany: Sozialforschungsstelle, pp. 74-77.

7. Do, A. \& Fernandes, C. (2020). Social innovation: a systematic literature review and future agenda research. International Review on Public and Non - Profit Marketing, Vol. 17 No. 1, pp. 23-40.

8. Doherty, B., Haugh, H. and Lyon, F. (2014), Social Enterprises as Hybrid Organizations: A Review and Research Agenda, International Journal of Management Reviews, Vol. 16 No. 4, pp. 417-436.

9. Douglas, H., (2015), Embracing hybridity: A review of social entrepreneurship and enterprise in Australia and New Zealand, Third Sector Review, Vol. 21 No. 1, pp. 5-30.

10. Dupuy, K., Ron, J., Prakash, A. (2016), “Hands Off My Regime! Governments' Restrictions on Foreign Aid to Non-Governmental Organisations in Poor and Middle-Income Countries", World Development. Vol. 84 pp. 299-311

11. Dykes, K., (2013), "Networks od Wind Energy Enthusiasts and the Development of the "Danish Concept" In Maegaard, P., Krenzem A., \& Palz, W. (eds) Wind Power for the World: The Rise of Modern Wind Energy, Part 1. Pan Standford Publishing, USA 
12. Easter, S., and Conway Dato-On, M. (2015), "Bridging Ties Across Contexts to Scale Social Value: The Case of a Vietnamese Social Enterprise", Journal of Social Entrepreneurship, Vol. 6 No. 3, pp. 320-351

13. Eckardt, S., Deepak, M. and Tuan Dinh, S. (2018), Vietnam's manufacturing miracle: Lessons for developing countries, Fraser Institute, (2017), Economic Freedom of the World in 2015, available at: https://object.cato.org/sites/cato.org/files/pubs/efw/efw2017/efw-2017-chapter-1.pdf

14. Eichler, G.M. \& Schwarz, E.J. (2019), "What Sustainable Development Goals Do Social Innovations Address? A Systematic Review and Content Analysis of Social Innovation Literature", Sustainability, Vol. 11 No. 2, pp. 522.

15. Gamble, W., (2011). Investing in Emerging Markets: The rules of the game, Apress, New York, USA.

16. Granovetter, M. (2005), "The Impact of Social Structure on Economic Outcomes", The Journal of Economic Perspectives, Vol. 19 No. 1, pp. 33-50.

17. Granovetter, M. (1985), "Economic action and social structure: The problem of embeddedness", American Journal of Sociology, Vol. 91 No. 481, pp. 481-510.

18. Granovetter, M. (1973), "The strength of weak ties", American Journal of Sociology, Vol. 78 No. 6, pp. 1360-1380.

19. Hansen, A., (2017), "Consuming doi moi: Development and middle class consumption in Vietnam", Journal of Social Sciences and Humanities, Vol. 3 No. 2.

20. Heiscala, R. (2007), "Social innovations: structural and power perspectives", in: Hamalainen, T and Heiscala, R. (eds), Social Innovations, Institutional Change and Economic Performance. Edward Elgar, pp. 52-79.

21. Herold, D. Farr-Wharton, B., Lee, K., and Groschopf, W. (2019), "The interaction between institutional and stakeholder pressures: Advancing a framework for categorising carbon disclosure strategies", Business Strategy and Development, Vol. 2, pp. 77-90

22. Higginbottom, G. (2004), "Sampling issues in qualitative research", Nurse Researcher, Vol. 12 No. 1, pp. 720.

23. Hiteva, R. \& Sovacool, B. (2017), “Harnessing social innovation for energy justice: A business model perspective", Energy Policy, Vol. 107, pp. 631-639.

24. Horgan, D. \& Dimitrijević, B. (2018), "Social Innovation Systems for Building Resilient Communities", Urban Science, Vol. 2 No. 1, pp. 13-28.

25. Indrakesuma, T. and Loh, J. (2012), Urban Poor's Everyday struggle in Vietnam, The Diplomat, available at: https://thediplomat.com/2012/10/hanoi-urban-poors-everyday-struggle/

26. Kjaer, U., (2013), “Local Political Leadership: The Art of Circulating Political Capital”, Local Government Studies, Vol. 39 No. 2, pp. 253-272.

27. Koirala, B.P. Araghi, Y., Kroesen, M., Ghorbani, A., Hakvoort, R.A. \& Herder P.M. (2018), “Trust, awareness, and independence: Insights from a socio-psychological factor analysis of citizen knowledge and participation in community energy systems", Energy Research and Social Science, Vol. 38, pp. 2214-6296.

28. Kooij, H., Oteman, M., Veenman, S., Sperling, K., Magnusson, D., Palm, J. and Hvelplund, F. (2018), "Between grassroots and treetops: Community power and institutional dependence in the renewable energy sector in Denmark, Sweden and the Netherlands", Energy Research and Social Science, Vol. 37, pp. 52-64.

29. Kruse, D.J., Goeldner, M. Eling, K. \& Herstatt, C. (2019), “Looking for a Needle in a Haystack: How to Search for Bottom-up Social Innovations that Solve Complex Humanitarian Problems". Journal of Product Innovation Management, Vol. 36 No. 6, pp. 671-694.

30. Leal, A. (2018), Power to the Poor in Laos brings electricity to (almost) all, available at https://blogs.worldbank.org/eastasiapacific/power-to-the-poor-in-laos-brings-electricity-toalmost-all: World Bank Blogs.

31. Lincoln, Y. and Guba, E. (1985), Naturalistic Inquiry. Beverly Hills, CA: Sage.

32. Luong, H. (2003), Wealth, Power and Inequality: Global Market, the state and local sociocultural dynamics - Postwar Vietnam: Dynamics of transforming a society, Oxford: Rowman and Littlefield Publishers.

33. Madriz-Vargas, R., Bruce, A., Watt, M., Mogolion, L. and Alverez, R. (2017), “Community renewable energy in Panama: a sustainability assessment of the "Boca de Lura" PV-wind-battery hybrid power system", Renewable energy and Environmental Sustainability, Vol. 2, pp. 1-7.

34. Markard, J., Raven, R., and Truffer, B. (2011), "Sustainability transitions: An emerging field of research and its prospects", Research Policy, Vol. 41, pp. 955-967.

35. Marsden, P. and Campbell, K. (1984), "Measuring Tie Strength", Social Forces, Vol. 63 No. 2, pp. $482-501$.

36. May, F and Diesendorf, M. (2018), "Who owns an energy transition? Strategic action fields and community wind energy in Denmark", Energy Research \& Social Science, Vol. 35, pp. 108-117. 
37. Maykut, P. and Morehouse, R. (1994), Beginning qualitative research: A philosophic and practical guide, London and Washington DC: Falmer Press.

38. Mulgan, G. (2006), "The Process of Social Innovation", Innovations: Technology, Governance, Globalization. Vol. 1 No. 2, pp. 145-162.

39. Mulgan, G. (2019), Social Innovation: How Societies Find the Power to Change, Policy Press, Bristol: UK.

40. Murray, R., Caulier-Grice, J. \& Mulgan, G. (2010), The Open Book of Social Innovation. London: National endowment for science, technology and the art.

41. National Economics University (2020), An interactive map of social impact businesses in Vietnam (imap), Center for Social Innovation \& Entrepreneurship, National Economics University, available online at https://imapvietnam.org/

42. Ngo, C. and Tarko, V. (2017), "Economic development in a rent-seeking society: socialism, state capitalism and crony capitalism in Vietnam", Canadian Journal of Development Studies, Vol. 39, pp. 481-499.

43. Nguyen, M., (2017), Vietnam prosecutes more oil firm officials for alleged mismanagement, Reuters, available at: https://www.reuters.com/article/us-petrovietnam-arrest/vietnam-prosecutes-more-oil-firmofficials-for-alleged-mismanagement-idUSKCN1BC4NM

44. Nicholls, J. (2007), Why measuring and communicating social value can help social enterprise become more competitive, Cabinet Office - Office of the Third Sector, November 2007, available at https://www.socialtraders.com.au/wp-content/uploads/2016/05/Why-Measuring-and-CommunicatingSocial-Value-Can-Help-Social-Enterprise-Become-More-Competitive.pdf

45. Nicholls, Alex, and Rafael, Ziegler. (2017), "An extended social grid model for the study of marginalization processes and social innovation.", CRESSI Working Papers No. 2/2015.

46. Nguyen, T., Nguyen, T.T., Hoangy, V.N., Wilson, C., and Managi, S. (2019), "Energy transition, poverty, and inequality in Vietnam", Energy Policy Vol. 132 pp.536-548

47. Oeij, P., Van Der Torre, W., Vass, F., and Dhondt, S. (2019), "Understanding social innovation as an innovation process: Applying the innovation journey model", Journal of Business Research, Vol. 101, pp. 243-254.

48. Popov, E.V., Veretennikova, A.Y., and Omonov, Z.K. (2016). Institutional Mechanism for Shaping Social Innovation. Social Development, Vol. 5 No. 47 pp. 57-75

49. Prybyla, J. (1966), "Soviet and Chinese Economic Aid to North Vietnam", The China Quarterly, Vol. 27, pp. 84-100.

50. Puumalainen, K., Sjogen, H., Syria, P., and Barraket, J, (2015), "Comparing social entrepreneurship across nations: An explanatory study of institutional effects", Canadian Journal of Administrative Sciences, Vol. 32 No. 4, pp. 276-287.

51. Sengupta, S., Sahay, A., \& Croce, F. (2018), "Conceptualizing social entrepreneurship in the context of emerging economies: An integrative review of past research from BRIICS", The International Entrepreneurship and Management Journal, Vol. 14 No. 4, pp. 771-803.

52. SI Drive, (2020), Atlas of Social Innovation, Technische Universität Dortmund, European Union FP7 Funded Project, available at https://www.socialinnovationatlas.net/map/

53. Smith, D., and Scarpaci, J. (2000), "Urbanization in Transitional Societies: An Overview of Vietnam and Hanoi", Urban Geography, Vol. 21 No. 8, pp. 734-757.

54. Sovacool, B., and Drupady, M. (2012), Energy Access, Poverty, and Development- The Governance of SmallScale Renewable Energy in Developing Asia. UK: Ashgate.

55. Suchman, M. C. (1995), "Managing legitimacy: Strategic and institutional approaches", Academy of Management Review, Vol. 20, pp. 571-610.

56. Sung, T. and Kim, D. (2017), "How chaebol restructuring after the 1997 crisis has affected corporate decision and performance in Korea: Debt financing, ownership structure, and investment", China Economic Journal, Vol. 10 No. 2, pp. 147-161.

57. Thayer, C. (2009), "Political Legitimacy of Vietnam's One Party-State: Challenges and Responses", Journal of Current Southeast Asian Affairs, Vol. 28 No. 4, pp. 47-70.

58. Urban, F., Siciliano, G., Wallbott, L., Lederer, M. and Nguyen, A., (2018), "Green transformations in Vietnam's energy sector", Asia and the Pacific Policy Studies, Vol. 5 No. 3, pp. 558-582.

59. Van, B., (2004). Viet Nam - A Transitional Tiger? Australia: ANU Press.

60. Vanham, P., (2018), "The Story of Viet Nam's economic miracle", https://www.weforum.org/agenda/2018/09/how-vietnam-became-an-economic-miracle/: World Economic Forum.

61. Vo Nhan, T. (1990), Vietnams Economic Policy since 1975. Singapore: Institute of South East Asian Studies. 
62. Voeten, J., De Haan, J., De Groot, G. (2015), “Understanding Responsible Innovation in Small Producers' Clusters in Vietnam through Actor-Network Theory", European Journal of Development Research, Vol. 27 No. 289, pp. 289-307.

63. Wirth, S. (2013), “Communities Matter: Institutional Preconditions for community renewable energy", Energy Policy, Vol. 70, pp. 236.

64. Yalcin-Riollet, M., Garabuau-Moussaoui, I., and Szuba, M. (2014), “Energy autonomy in Le Mene: A French case of grassroots innovation", Energy Policy, Vol. 69, pp. 347.

65. Yin, R.K. (1994), Case Study Research Design and Methods: Applied Social Research and Methods Series. 2nd edn, Thousand Oaks, CA: Sage Publications Inc.

66. Yin, R.K. (2014), Case-study research: Design and methods. 5th edition, London: Sage Publications. 


\begin{tabular}{|c|c|c|c|}
\hline Interviewee & ID & Location & Research Conducted \\
\hline Energy Social Enterprise CEO & SE1 & Hanoi Floating Village & Interview, Observation \\
\hline Eco-Tourism Enterprise CEO & SE2 & Hanoi Floating Village & Interview, Observation \\
\hline Village Elder & V02 & Hanoi Floating Village & Interview \\
\hline Village Leader & V01 & Hanoi Floating Village & Interview, Tour \\
\hline $\begin{array}{c}\text { Professor } \\
\text { Social Incubator Manager } \\
\text { Engineer }\end{array}$ & $\begin{array}{l}\text { P01 } \\
101 \\
\text { P02 }\end{array}$ & University in Hanoi & Focus Group \\
\hline Social Incubator Investor & 102 & University in Hanoi & Observation \\
\hline $\begin{array}{c}\text { Member of Cat Ba Management } \\
\text { board }\end{array}$ & G02 & Cat Ba Island & $\begin{array}{c}\text { Interview, } \\
\text { Observation, Tour }\end{array}$ \\
\hline Representative of local government & G01 & Cat Ba Island & Observation \\
\hline $3 \times$ Biogas Pig Farmers & $\begin{array}{l}\text { F01 } \\
\text { F02 } \\
\text { F03 }\end{array}$ & Cat Ba Island & $\begin{array}{l}\text { Interviews, } \\
\text { Observation }\end{array}$ \\
\hline Former Biogas Pig Farmer & F04 & Cat Ba Island & Interview \\
\hline $3 \times$ Floating Farmers & $\begin{array}{l}\text { F05 } \\
\text { F06 } \\
\text { F07 }\end{array}$ & Cat Ba Island & Interview, Observation \\
\hline
\end{tabular}




\section{Macro Level}

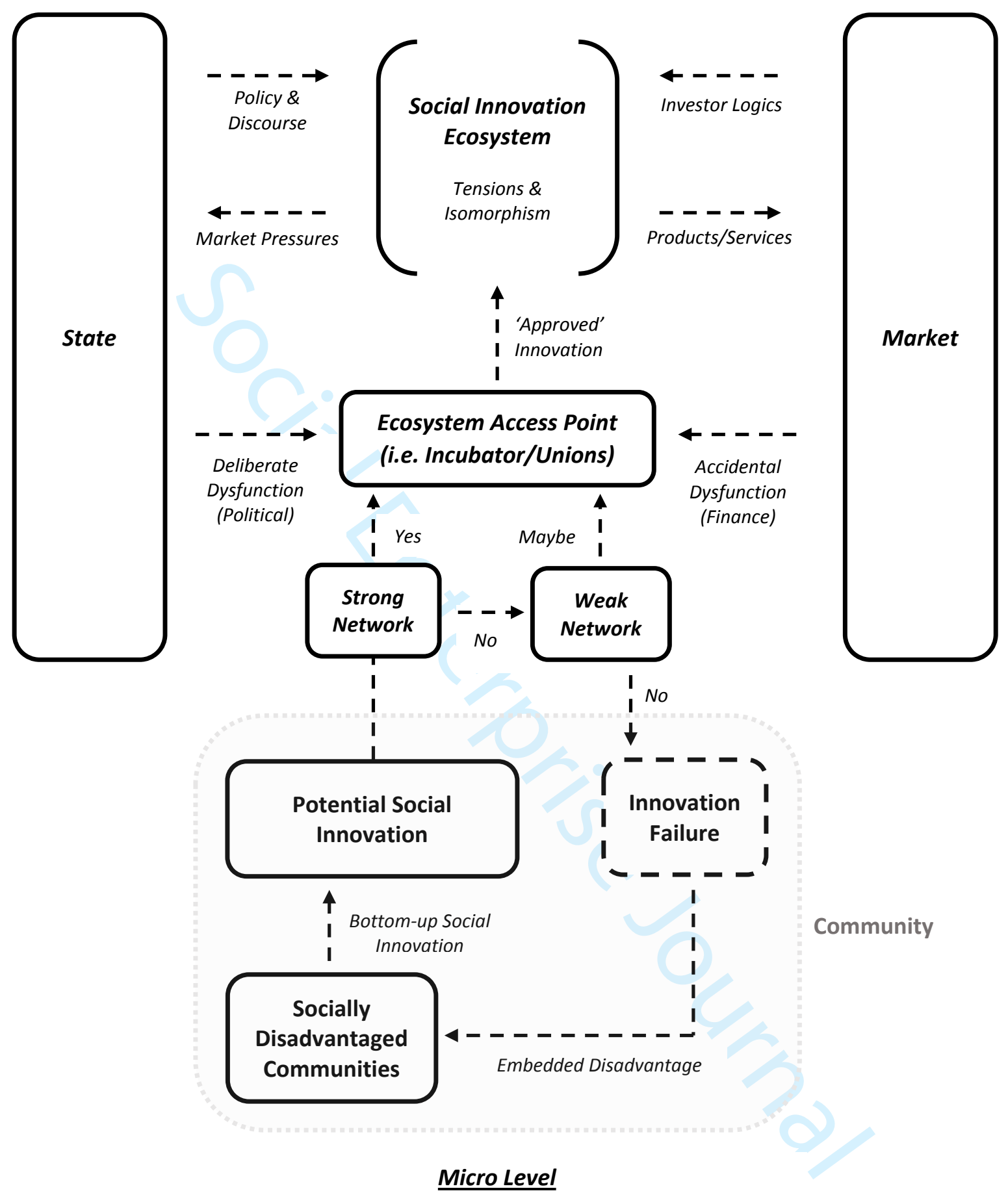

Figure 2 - Barriers to Social Innovation in Vietnam's Community Energy Sector 